polyradiculoneuropathy of subacute onset, seems to be more in keeping with an immunologically induced demyelination.

I thank Dr E C Hutchinson, North Staffordshire Royal Infirmary, for his permission to report this case.

${ }^{1}$ Russell RWR. Giant-cell arteritis. A review of 35 cases. $Q \mathcal{F}$ Med 1959; 28:471-89.

2 Warrell DA, Godfrey S, Olsen EGJ. Giant-cell arteritis with peripheral neuropathy. Lancet $1968 ; \mathrm{i}: 1010-3$.

${ }^{3}$ National Institute of Health. Diagnostic criterions for Guillain-Barré meningitis caused by Haemophilus infuenzae. I $A M A$ 1978;240: 1709-11.

${ }^{4}$ Hazleman B, Goldstone A, Voak D. Association of polymyalgia rheumatica and giant-cell arteritis with HLA-B8. $\mathrm{Br}$ Med f 1977;ii:989-91.

${ }^{5}$ Hughes RAC. In: Rose FC, ed. Clinical neuroimmunology. Oxford: Blackwell Scientific Publications, 1979.

(Accepted 2 October 1979)

Regional Department of Neurology, Derbyshire Royal Infirmary, Derby DE1 2QY

R N CORSTON, MB, MRCP, senior registrar

\section{Pregnancy attributable to interaction between tetracycline and oral contraceptives}

Various drugs, including antibiotics, may cause failure of contraception and breakthrough bleeding in patients on oral contraceptives. ${ }^{1}$ Early reports implicated rifampicin, ${ }^{2}$ which was later shown to increase the rate of hepatic metabolism of ethinyloestradiol and norethisterone. ${ }^{1}$ There have been three cases of pregnancy in women taking ampicillin. ${ }^{3}$ We cannot find any report of either breakthrough bleeding or pregnancy attributable to tetracycline in a woman taking oral contraceptives. We report such a case.

\section{Case history}

The patient, a 20-year-old student, had been taking oral contraceptives for four years. Her only complaint had been of an increase in left-sided headaches. For the last two years she had taken Microgynon 30 (ethinyloestradiol $30 \mu \mathrm{g}$, D-norgestrol $150 \mu \mathrm{g}$ ) and had had no breakthrough bleeding. On 16 October 1978 she had a normal withdrawal bleed. On 20 October she started the next course of Microgynon and also (for sinusitis) a five-day course of tetracycline $500 \mathrm{mg}$ six hourly for three days and $250 \mathrm{mg}$ six hourly for two days. She completed the course on the 24 October. She did not forget to take her oral contraceptive. She had no diarrhoea or vomiting but had only a very light two-day withdrawal bleed on 14 and 15 November 1978 . She continued to take her oral contraceptive for a further two months until seen at the family planning clinic on 8 January 1979. Her uterus was then the size of at least a 12-week pregnancy. This would have corresponded with a previous menstrual period on about the 15 October, and indicated that she must have ovulated either when she was taking the tetracycline or in the week after. Termination confirmed the clinical assessment of the duration of pregnancy.

\section{Comment}

The time course of this history in a woman who had been taking oral contraceptives for four years with no problems strongly suggests that the tetracycline contributed to the failure in contraception. In addition to the reports of pregnancies associated with rifampicin ${ }^{2}$ and ampicillin, ${ }^{3}$ pregnancies have been reported in two women taking either sulphamethoxypyradizine or chloramphenicol ${ }^{4}$ and also an increased incidence of breakthrough bleeding in women on phenoxymethylpenicillin, neomycin, or nitrofurantoin. ${ }^{1}$ The mechanism of the interaction is unknown but a decrease in urinary oestriol output has been noted in pregnant women taking ampicillin, ${ }^{5}$ phenoxymethylpenicillin, or neomycin. ${ }^{1}$ Therefore the enterohepatic circulation of contraceptive steroids may be interrupted by inhibition of the gut bacteria normally responsible for hydrolysis of steroid conjugates. ${ }^{4}$ This would result in lower-than-normal concentrations of circulating steroids. There seems no reason why tetracycline should not cause a similar change.
With the widespread use of low-dose oestrogen contraceptives such interactions may well occur more often. Tetracyclines are used for a wide range of infections including pelvic inflammatory disease and non-specific urethritis. One of us has seen a second case of breakthrough bleeding associated with a course of tetracycline. We therefore think that doctors should be aware of the potential problem. We would advise that women taking low-dose oral contraceptives should take extra precautions against conceiving in any cycle during which antibiotics are given.

${ }^{1}$ Stockley I. Interactions with oral contraceptives. Pharmaceut $\mathcal{F} 1976$;216: 140-3.

${ }^{2}$ Reimers D, Nocke-Finck L, Breuer H. Rifampicin and the "pill" do not go well together. $f A M A 1974 ; 227: 608$.

${ }^{3}$ Dossetor EJ. Drug interactions with oral contraceptives. $\mathrm{Br} \mathrm{Med} \mathcal{F} 1975$; iv:467-8.

4 Buck DJ, Breckenridge AM. Drug interactions with oral contraceptives. IPPF Med Bull 1978;12:1-2.

${ }^{5}$ Pulkkinnen MO, Willman K. Reduced maternal plasma and urinary estriol during ampicillin treatment. Am f Obstet Gynecol 1971;109: 893-6.

(Accepted 19 October 1979)

Family Planning Association of Western Australia, 233 Adelaide Terrace, Perth, Western Australia

JANET F BACON, MB, medical officer

University of Western Australia, Nedlands, Western Australia 6009 GILLIAN M SHENFIELD, $\mathrm{DM}, \mathrm{MRCP}$, senior lecturer in clinical pharmacology

\section{Diet and ulcerative colitis}

The apparent rarity of ulcerative colitis in developing countries together with the ability of dietary fibre to affect colonic function and bacterial metabolism have led to suspicions that a low intake of fibre may be a causal factor in this disease. ${ }^{12}$ People who develop Crohn's disease (a closely related condition) show significant differences in diet from matched controls, eating less raw fruit and vegetable fibre and more refined sugar. ${ }^{3}$ To investigate whether ulcerative colitis is preceded by an unusual diet we have compared the diet before illness of patients with newly diagnosed colitis with that of closely matched, healthy subjects.

\section{Subjects, methods, and results}

Thirty consecutive newly diagnosed patients ( 17 men, 13 women) were studied. The diagnosis of ulcerative colitis was based on the findings of barium radiology, sigmoidoscopy, and rectal biopsy. In 10 patients the disease extended proximal to the splenic flexure, in five it was limited to the rectum, and in the remaining 15 it was of intermediate extent. The median duration of symptoms before diagnosis was two months (range 1-18).

All patients were interviewed within three months of diagnosis. A single dietitian used the dietary history method ${ }^{4}$ to question each patient about his or her habitual diet before illness. Using a specially designed questionnaire, she determined the frequency of consumption and size of helpings of each of a comprehensive range of foods and drinks. ${ }^{3}$ The data were analysed to determine the average daily intake of different food components with the use of a computer programme compiled from McCance and Widdowson's food tables. ${ }^{5}$

Dietary intake of 30 patients with ulcerative colitis before their illness and that of 30 matched, healthy controls. Results given in g/day as means $\pm S E$ of mean unless stated otherwise

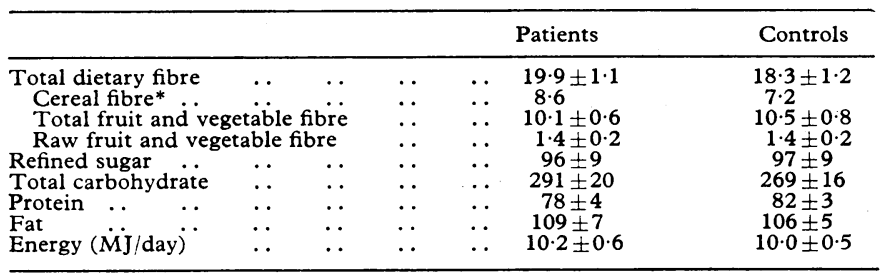

* Median value

Conversion: SI to traditional units-Energy: $4 \cdot 2 \mathrm{MJ} \approx 1000 \mathrm{kcal}$. 